\title{
SURVEY OF LIGHT POLLUTION OF ARAK CITY BY USING OF DMSP AND SUONI- NPP SATELLITE IMAGERY
}

\author{
M. O. Maghsoodi ${ }^{1}$,A. Kazemi ${ }^{1 *}$, A. Hedayati Aghmashadi ${ }^{1}$, M.R. Gili ${ }^{2}$ \\ ${ }^{1}$ Arak University, Agriculture and Natural Resources Faculty, Department of Environmental Engineering, Arak, Iran - \\ (m.maghsoodikelardashti, a_kazemi, amir_hedayati)@araku.ac.ir \\ ${ }^{2}$ Malayer University, Natural Resources and environment Faculty, Department of Environmental Engineering, Malayer, Iran - \\ rsgreza@yahoo.com
}

KEY WORDS: Light pollution, DMSP Satellite, Suomi-NPP Satellite, Imagery.

\begin{abstract}
:
Today, the use of remote sensing techniques and satellite images of night lights has immensely assisted in investigating this kind of pollution. The objectives of this research is to survey the light pollution of the city of Arak in Iran for the years 1997 and 2009 , by utilizing satellite images of DMSP night lights and for the years 2013 through 2018, by taking advantage of Soumi-NPP satellite images of night lights and exploring its connection to the city's electricity power consumption for street lighting. The night light images of the DMSP and NPP satellites, depending on the degree of light intensity, were each, in segregation, categorized into five classes of light pollution levels, ranging from very high to very low levels. Next, light pollution maps were extracted from classified images and then the connection of the 'high and very high' classes of light pollution with electric power consumption for street or road lighting was surveyed in these years. Results of the study indicates that the amount of light pollution in these years was in relevance with road or street lighting, as in the years when the amount of electricity consumption for road lighting was high and its role in connection with light pollution was also in great percentages; and in years with a decrease in electricity consumption for road lighting, lower percentages were displayed.
\end{abstract}

\section{INSTRUCTIONS}

The presence of excessive artificial lighting brings about a kind of environmental pollution in the night sky, which is critical, though recognized to a lesser extent; and has destructive environmental, biological and economic impacts, including energy losses, known as light pollution. Light pollution was first identified by astronomers in the 1930s .Because light scattered from the shining sky of the city, it prevented the visual observation of low-light celestial bodies near the cities (Riegel, 1973). The problem of light pollution has been important since the 1960s due to urban development and the use of artificial lights and bulbs at night (Hosseini and Nasiri, 2007). This kind of pollution is a problem that affects almost every urban area and is produced by a large number of light sources that throw light into the sky, and because of the presence of dust and aerosols in the atmosphere, the light scattered by the sky Clarifies (Barducci et al., 2006).

\section{LITERATURE REVIEW}

The present study was conducted in Arak, one of the metropolitan areas of Iran and the center of Markazi province. The city of Arak is located at an equator of $34^{\circ}, 4^{\prime} 48^{\prime}$ "in the northern hemisphere. It is also on the meridian of $49^{\circ}, 42^{\prime}$ from the Greenwich meridian. Arak is known as the industrial capital of Iran. The objectives of this research is to survey the light pollution of the city of Arak in Iran for the years 1997 and 2005, by utilizing satellite images of DMSP night lights and for the years 2013 through 2018, by taking advantage of Soumi-
NPP satellite images of night lights and exploring its connection to the city's electricity power consumption for street lighting. The paper must be compiled in one column for the Title and Abstract and in two columns for all subsequent text. All text should be single-spaced, unless otherwise stated. Left and right justified typing is preferred.

\section{PROPOSED METHOD}

In order to execute this, upon preparing the satellite images for night lighting for the relevant years; and extracting the area of study under consideration with the Arc GIS 10.2 Software, the range of the degree of light of each image was determined and the night light images of the DMSP and NPP satellites, depending on the degree of light intensity, were each, in segregation, categorized into five classes of light pollution levels, ranging from very high to very low levels. Subsequently, in accordance with the total number of pixels which each image encompasses and comprises of, from the levels of light pollution; a level percentage of light pollution was determined for each year and a set of percentage levels, namely, 'high and very high' on the basis of light pollution surveys was defined. Next, light pollution maps were extracted from classified images and then the connection of the 'high and very high' classes of light pollution with electric power consumption for street or road lighting was surveyed in these years. 


\section{RESULTS}

On investigating the results of the classes of light pollution in respect to the DMSP satellite relative to the years 1997 and 2005 respectively, demonstrated a high level of $93.5 \%$ and $96.7 \%$ of night lighting. Similarly, in studying the amount of electricity consumption for road lighting in these years, it has been observed that, power consumption has increased by 18905013 million KW/hour in 2009 compared to 1997 for road lighting. In studying the results of the classes of light pollution of the NPP satellite in relative to the years 2013 through 2018, with due attention to the implementation of a plan regarding the optimal alleviation or improvement of road lighting in 2012, it has been noted that the high level of night lighting have illustrated a significant decrease of $1.1 \%$ in 2013 and $1.4 \%$ in 2014. Likewise, an investigation of its relative with road lighting shows a decrease of 7978316 million KW/hour of road lighting power consumption in 2013 compared to the year 2005. But it has been observed that in 2015, the consumption of electric power for street lighting in comparison to 2014 had increased by 1104724 million KW/hour; whereas, this increase in the years 2015 was 654954 thousand KW/hour, there was an increase of 2233607 million KW/hour in 2017 in respect to 2016 and lighting pollution maps also depict an increment of $3.3 \%, 3.8 \%$ and $9.6 \%$ in the years 2015 through 2017 respectively. In 2018, road lighting demonstrated a decrease of 1116804 million KW/hour and a high level of night lights, which showed a decrement of $1.4 \%$ and $9.6 \%$ in 2017, registered at $8.2 \%$ in 2018 .

Table 1- Percentage of light pollution in 1997-2009

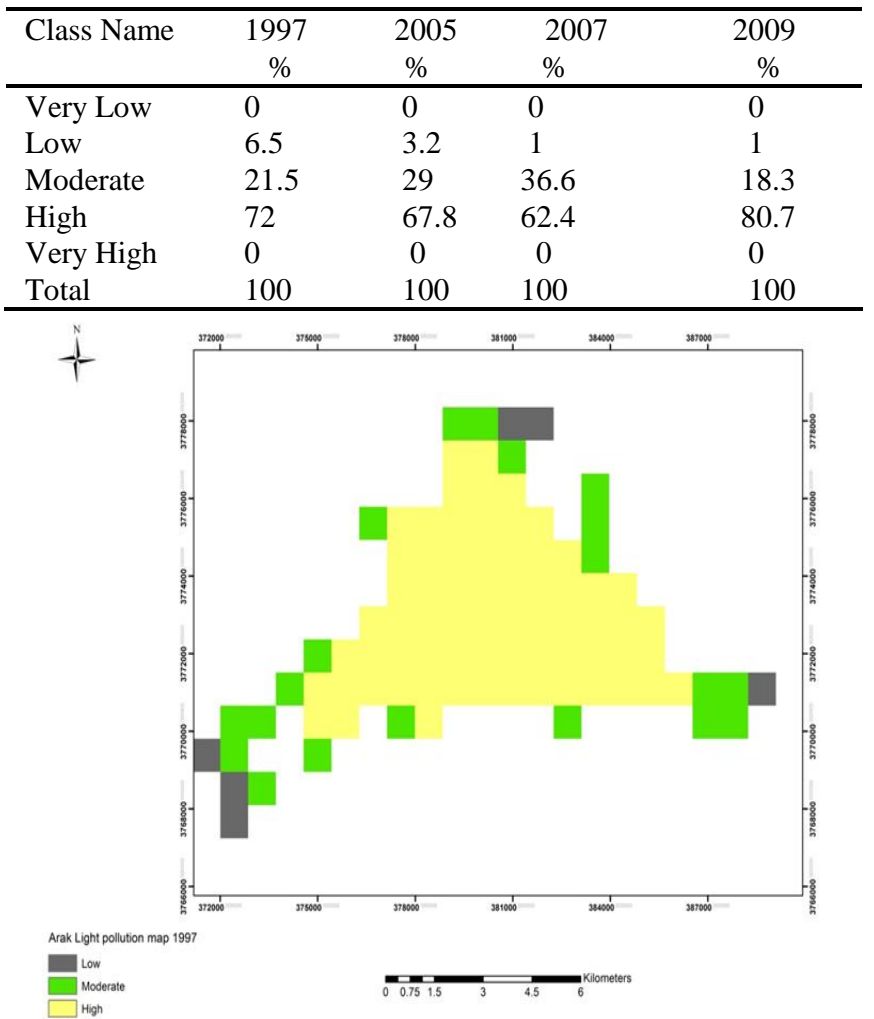

Figure 1. Light pollution map 1997

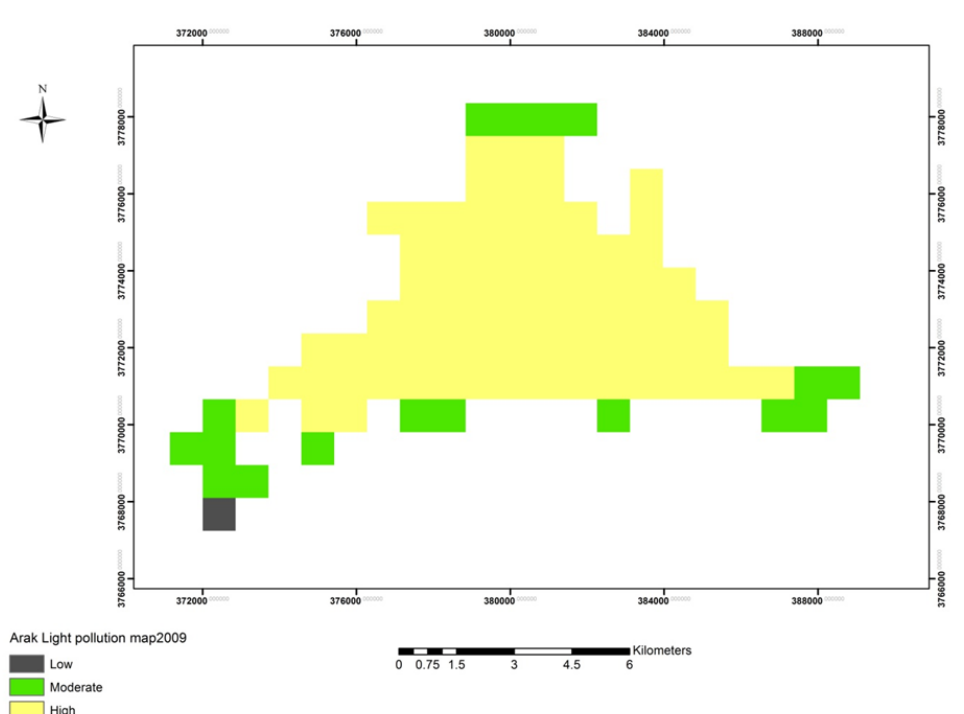

Figure 2. Light pollution map 2009

Table 2- Light pollution in 2013-2018

\begin{tabular}{|lcccccc|}
\hline Class Name & $\begin{array}{c}2013 \\
\%\end{array}$ & $\begin{array}{c}2014 \\
\%\end{array}$ & $\begin{array}{c}2015 \\
\%\end{array}$ & $\begin{array}{c}2016 \\
\%\end{array}$ & $\begin{array}{c}2017 \\
\%\end{array}$ & $\begin{array}{c}2018 \\
\%\end{array}$ \\
\hline Very Low & 15.15 & 14.6 & 11.3 & 14 & 8 & 9.3 \\
Low & 53.45 & 53.7 & 45.45 & 42.2 & 40 & 43 \\
Moderate & 30.3 & 30.3 & 39.95 & 40 & 42.4 & 39.5 \\
High & 1.1 & 1.4 & 2.2 & 3 & 8 & 7.1 \\
Very High & 0 & 0 & 1.1 & 0.8 & 1.6 & 1.1 \\
Total & 100 & 100 & 100 & 100 & 100 & 100 \\
\hline
\end{tabular}



Figure 3. Light pollution map 2013 


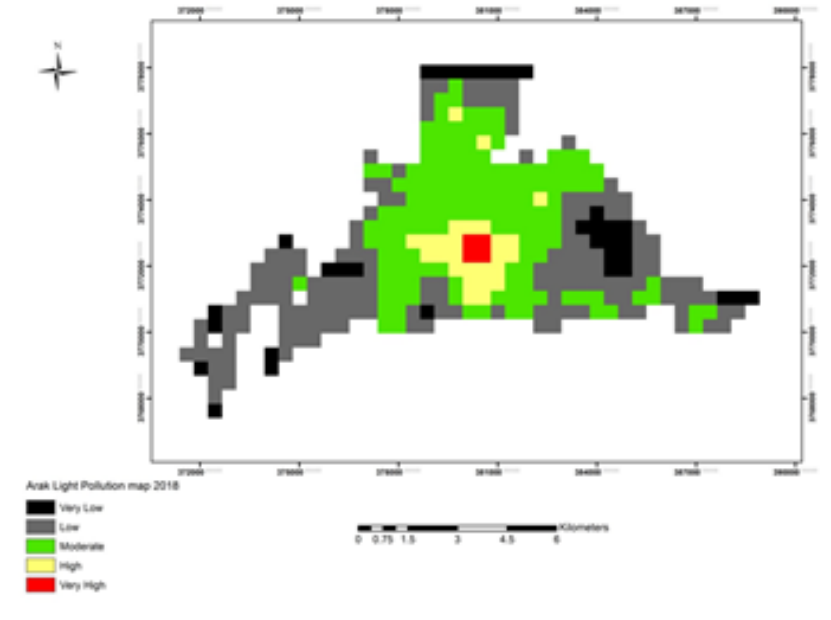

Figure 4. Light pollution map 2018

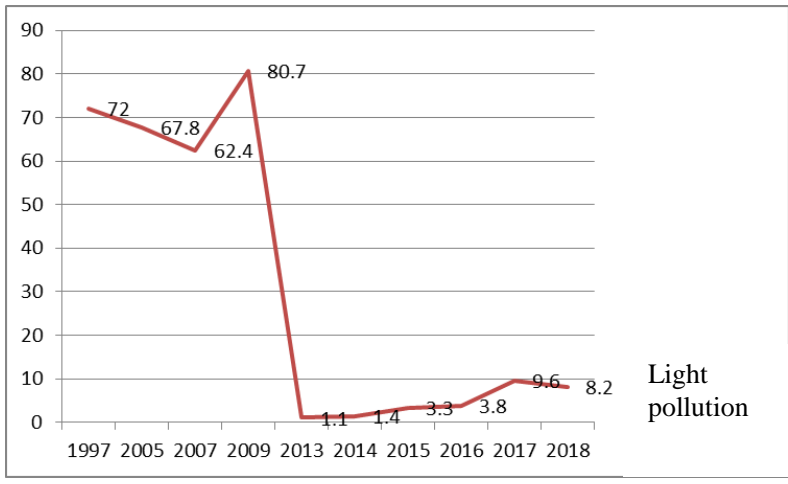

Figure 5. Chart of light pollution from 1997 to 2018

\section{CONCLUSIONS}

Results of the study indicates that the amount of light pollution in these years was in relevance with road or street lighting, as in the years when the amount of electricity consumption for road lighting was high and its role in connection with light pollution was also in great percentages; and in years with a decrease in electricity consumption for road lighting, lower percentages were displayed.

\section{REFERENCES}

Akesson S, Walinder G, Karlsson L and Ehnbom S (2001). Read warbler orientation: initiation of nocturnal migratory flights in relation to visibility of celestial cues at dusk. Anim. Behav. 61(1): 181-189.

Albers S, Duviscoe D (2001). Modeling light pollution from population data and implication for national park service's lands.
Barducci A, Benvenuti M, Bonora L, Castagnoli F, Guzzi D, Marcoionni P and Pippi L (2006). Hyper spectral remote sensing for light pollution monitoring. Annals of Geophysics.49 (1).

- Bennie J, Davies TW, Duffy JP, Inger R and Gaston KJ (2014). Contrasting trends in light pollution across Europe based on satellite observed night time lights. Sci. Rep

BurtonW (2001). The novac-DMSP light pollution map project. Web site:http// www.stellafane.com/.

Butt MJ (2012). Estimation of light pollution using satellite remote sensing and geographic information system techniques. Department of meteorology, king Abdolaziz University.

.Cha JS, Lee JW, Lee WS and GU JH (2014). Policy and Status of Light pollution Management in Korea. Lighting Research and Technology, 46(1): 78-88.

Chalkias C, Petrakis M, Psiloglou B and Lianon M (2006).Modeling of light purgation in suburban areas using remotely sensed imagery and GIS. Journal of environmental management, 79, 57-63.

Chepesiuk R (2009).Missing the dark health effects of light pollution. Environmental Health Perspectives, 117: 20-27

Cinzano P, Falchi F and Elvidge CD (2001).The first world Atlas of the artificial night sky Brightness. Monthly Notices of the Royal Astronomical society, 328 (3): 689-707.

Cole TA, Wanik DW, Molthan AL, Román MO, Griffin RE (2017). Synergistic Use of Nighttime Satellite Data, Electric Utility Infrastructure, and Ambient Population to Improve Power Outage Detections in Urban Areas. Remote Sens. 2017, 9,286

. Croft TA (1978). Night time Images of the earth from space. Scientific American, 239:68-79.

Elsahragty M, Kim JL (2015). Assessment and Strategies to Reduce Light Pollution using Geographic Information Systems. Procedia Engineering, 118 ( 2015 ) 479 - 488.

Elvidge, C.D., Baugh, K., Zhizhin, M., Hsu, F.C., Ghosh, T., 2017. VIIRS night-time lights. Int J Remote Sens 38 (21), $5860 \mathrm{e} 5879$.

Elvidge, C.D., Baugh, K., Zhizhin, M., Hsu, F.C., 2013. Why VIIRS data are superior toDMSP for mapping nighttime lights. Proc. Asia-Pacific Adv. Netw. 35, 62e69

Elvidge CD, Baugh KE, Kihn EA, Kroehl HW, Davis ER and Davis C (1997).Relation between satellite observed visible-near infrared emissions Population, and energy consumption. Int J Remote Sens, 18:13.

.Falchi F, Cinzano P, Duriscoe D, Kyba CM, Elvidge CD, Baugh K, Portnov B, Ribnikova NK and Furgoni R (2016). The 
new world atlas of artificial night sky brightness.Sci.Adv. 2: e1600377.

Gallaway, T., Olsen, R., \& Mitchell, D. (2010). The economics of global light pollution. Ecological Economics, 69, 658-665

Garstang RH (1986). Model for Artificial Night-sky illumination. Joint institue for laboratory Astrophysics, university of colorado and National Bureau Of Standads, Boulder,Colorado 80309

Gaston KJ, Davies TW, Bennie J and Hopkins J (2012). Review: Reducing the ecological consequences of night-time light pollution:Options and developments.J.Appl.Ecol.49(6), 1256-1266.

Han P, Huang J, Li R, Wang L, Hu Y, Wang J and Huang w .2014. Monitoring Trends in Light Pollution in China Based onNighttime Satellite Imagery. Remote Sens, 6, 5541-5558;

. Hansen J (2001). Light and night, shift work and breast cancer risk.Journal of the National cancer institue, 93(20): 1513-1515.

Hosseini SS, Nasiri S (2007). Measurement of light pollution at the Iranian National Observatory. International Astronomical Union.

IDA. International Dark-Sky Association. Assessed from http://www.darksky.org/ on July 11, 2014.

Jiang W, He G, Ni Y and Ma R (2017). Assesment of Light pollution Impact on Protected areas in Cina. The international archives of the photogrammetry, Remote sensing and spatial information sciences, volume XL11-2/W7, Wuhan,China.

Khorram A, Yusefi M and Fardad M (2014). Assessment of light pollution in Bojnord city using remote sensing data. Int $\mathrm{J}$ Env Health Eng ;3 (1):19

Kiran Chand TR, Badarinath KVS , Elvidge CD ,Tuttle BT (2009)Spatial characterization of electrical power consumption patterns over India using temporal DMSP-OLS night-time satellite data, International Journal of Remote Sensing, 30:3, 647-661

Muro, M. Light pollution-development blocked near Tucson telescopes. Science 1999, 283, 469

.Peters A, Verhoeven KJ (1994). Impact of artificial Lighting on the sea ward orientation of hatchling logger head turtles.J.herpetol. 112-114

Riegel KW (1973). Light pollution. Science, 179: 1285-1291.

Rodriguez, A.; Rodriguez, B.; Curbelo, A.J.; Perez, A.; Marrero, S.; Negro, J.J. Factors affecting mortality of shearwaters stranded by light pollution. Anim. Conserv. 2012, $15,519-526$
. Scapini F, Audoglio M, Chelazzi L, Colombini I and Fallaci M (1997). Astronomical, Land scape and climatic factors influencing oriented movements of Talitrus saltator in nature.Mar.Biol, 128 (1): 63-72.

Schernhammer EvaS, Laden f, Speizer FE, Willett WC, Hunter DJ, Kawachi L and Colditz GA (2001). Rotating night shift and risk of Breast cancer in Women Participating in the nurses' Health study. journal of National cancer Institute, 93(20):15631568

Wu J , He S, Peng J, Li W Zhong X.(2013). Intercalibration of DMSP-OLS night-time light data by the invariant region method. International Journal of Remote Sensing. Vol. 34, No. 20, 7356-7368 